Military Technical College, Kobry El-Kobbah, Cairo, Egypt

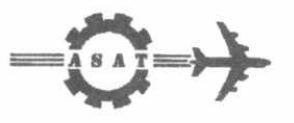

$9^{\text {th }}$ International Conference On Aerospace Sciences \& Aviation Technology

\title{
VEHICLE STRUCTURE MODELING AND ANALYSIS APPLYING COMPOSITE MATERIALS
}

\author{
EL-SOALY, A. ${ }^{*}$, MOUSSA, M.M. ${ }^{* *}$, RABEEH, B.M. ${ }^{\star *}$, AND ELTAHER, H.M. **
}

\begin{abstract}
:
The automotive industry is faced with an unprecedented challenge of producing cars that yield more miles per gallon and fewer pollutant. A lighter vehicle means lighter materials which in the same time fulfill safety requirements. In this study, modeling and analysis of the vehicle frame and body have been performed to anticipate the dimensions, weight and percentage of weight reduction when replacing the conventional materials with composite materials. Both steel and carbon fibers volume fractions affected the percentage of frame weight reduction but in an opposite way. The frame deformations under bending or torsion for both steel and carbon fiber composite having the same volume fraction are nearly the same. Boron / epoxy body panels has the least thickness and the highest percentage of weight reduction. Boron /aluminum was found to be a good alternative material for steel box beams used in the integral vehicle structure.
\end{abstract}

\section{KEY WORDS :}

Automotive, Structure, Composite Materials

\section{INTRODUCTION:}

In order to produce a lighter vehicle, many factors are considered, and the vehicle structure is the main dominating factor. Thorough studies of the vehicle structural mechanics is needed, so that in the way of producing a lighter, more fuel economic, and an environment friendly vehicle [1], the occupant safety should not be sacrificed [2]. Several approaches were investigated in order to achieve the goal of producing a lighter and safer vehicle [3]. One of the approaches was to downsize the vehicle, especially after 1973. Another approach was to substitute the conventional structural materials, which give the same or better performance, but with less weight.

\footnotetext{
* Prof. Dr. Higher Inst. Of Technology, Tenth of Ramadan .

** Egyptian Armed Forces.
} 
The objective of this work is to study the vehicle structural mechanics for replacement of conventional materials with composite materials in automotive structural parts. A real vehicle frame was investigated when replaced with aluminum matrix reinforced with steel fibers one time and carbon fibers another time and the effect on weight reduction was calculated. The replacement of vehicle body panels with non-conventional materials was investigated mathematically on the basis of material stiffness. Finally, a frame-less vehicle was also investigated for weight reduction when using various materials other than steel. This was accomplished with the aid of finite element method.

\section{MODELING AND ANALYSIS OF VEHICLE FRAME :}

A real frame of a commercial truck was considered. The truck technical data are given in Fig. 1. , Fig. 2., and Table 1.

\subsection{Defining the Loads:}

The loads acting on the frame were defined [4],[5], analyzed and the axial force, bending and twisting moments were calculated (Appendix $A$ ).

\subsection{Choice of Cross Section :}

Three different standard cross section shapes ( W, S and C) for the frame were tried to determine which one is the best. The stresses due to the frame loading were calculated using simple stress relations [6], then divided by the area of the section for comparison:

$$
\sigma= \pm F / A \pm M \cdot y / /
$$

where :

$\sigma \quad$ normal stress on beam cross section

A beam cross section area

$M \quad$ total bending moment $\left(M_{b}+M_{p}\right)$

I area moment of inertia of the section about the centroidal axis.

$Y$ distance from the point where stress is calculated to the centroidal axis.

It was found that the $\mathrm{S}$ - section has the least stress per unit area and was chosen to be the section of the frame. Using structural steel with yield strength of $400 \mathrm{MPa}$ as the material for the frame, the $S 150 \times 26$ section was found to be reasonable.

\subsection{Replacing Steel by Composite Materials for Weight Reduction :}

A complete analysis of the mechanics of fibrous composites is given in reference [7]. Since the mass percentage of reduction is calculated for the same length of the frame, so calculating the mass per unit length is satisfactory.

Mass per unit length for an isotropic material $(\mathrm{m})$ :

$m=A \cdot \rho$

A cross section area of isotropic material 
$\rho$ density of isotropic material

Mass per unit length for composite material $\left(m_{c}\right)$ :

$m_{c}=A_{c} \cdot \rho_{c}$

$\mathrm{A}_{c} \quad$ cross section area of composite material

$\rho_{c} \quad$ density of composite material

$\rho_{c}=\rho_{f} \cdot V_{f}+\rho_{m} \cdot V_{m}$

$\rho_{f} \quad$ density of fiber material

$\rho_{\mathrm{m}} \quad$ density of matrix material

$V_{f} \quad$ fiber volume fraction

$V_{m} \quad$ matrix volume fraction

Percentage of weight reduction (per) is :

$$
(\text { per })=\left(\left(m-m_{c}\right) / m\right) \cdot 100
$$

For the steel frame with section $\mathrm{S} 150 \times 26\left(\mathrm{~A}=3271 \mathrm{~mm}^{2}, \rho=7830 \mathrm{~kg} / \mathrm{m}^{3}\right)$ the mass per unit length is $25.71 \mathrm{~kg} / \mathrm{m}$. Using atuminum as the matrix material and two different types of fibers with properties given in Table 2. [8],[9], the stress in the composite frame is calculated using Eqs. $(A 12, A 14, A 15)$ and the analysis of the mechanics of composite materials. The frame cross section area is varied until a suitable value is reached. Substituting this value in Eq. (3), the mass per unit length of the composite frame can be calculated for a range $(0.1-1.0)$ of fiber volume fraction for both types of fibers. Then, the percentage of weight reduction is calculated from Eq. (5).

The results are shown in Fig. 3. It is shown that by increasing the steel fiber volume fraction the percentage of weight reduction decreases as a result of the increase in the mass per unit length, as the density of fiber material (steel) is higher than the density of matrix material (aluminum). Accordingly, by increasing the carbon fiber volume fraction, the percentage of weight reduction increases.

\subsection{Finite Element Modeling and Analysis of Frame :}

A- Under bending moment :

Finite element method ( ANSYS 5.4) is used to calculate the deformation and stresses in the composite frame under bending moment for both types of reinforcements with 0.3 fiber volume fraction. The results are given in Fig. (4-7). It is shown that the frame deformation in the $Y$ - direction for both types of composites are nearly the same as the stiffness is $228 \mathrm{GPa}$ for carbon fiber and $200 \mathrm{GPa}$ for steel fiber ( Table 2.). Comparing the stresses in the Z-direction, the value is $833 \mathrm{MPa}$ for carbon reinforced frame and $870 \mathrm{MPa}$ for steel reinforced frame, which are nearly the same. But knowing that the yield strength is $1034 \mathrm{MPa}$ for steel fibers and $4000 \mathrm{MPa}$ for carbon fibers, a large amount of cut down in the cross section area of the carbon reinforced frame is possible, which translates into a large amount of weight reduction. 
B- Under torsion :

Finite element method is used to calculate the deformation and stresses in the composite frame under torsion for both types of reinforcements with 0.3 fiber volume fraction. The results are given in Fig. (8-11). The frame deformation in the $X$ - direction for both types of composites are nearly the same due to the nearly equal stiffness of both fibers. Comparing the shear stresses in the XY-direction, the value is $337 \mathrm{MPa}$ for carbon reinforced frame, and $340 \mathrm{MPa}$ for steel reinforced frame, which are almost the same. But due to the large value of yield strength of the carbon fibers relative to that for the steel fibers, a large amount of cut down in the cross section area of carbon reinforced frame is possible, consequently a large amount of weight reduction.

\section{REPLACING CONVENTIONAL BODY PANELS MATERIAL BY COMPOSITE MATERIAL :}

The design of most body panels is governed by stiffness requirements [10]. The choice of an alternative material depends on the loading, the boundary conditions, the size and curvature of the panel. Since the thickness is the only variable in the redesign of panels, an approximate approach can be used to obtain a near optimal panel design.

The panel stiffness (S) of a support free region can be approximated as :

$$
S=E \cdot t^{a}
$$

Where :

E Young's Modulus for the panel material

$t$ panel thickness

a stiffness parameter

$\alpha$ is a function of panel curvature, loading, and boundary conditions. A value of 2.2 for $\alpha$ is determined experimentally and by the finite element solution [10], Hence : .

$$
\left(S_{a} / S_{b}\right)=\left(E_{a} / E_{b}\right) /\left(t_{a} / t_{b}\right)^{a}
$$

where a refers to alternative material and $b$ to the base material. For an equal stiffness design :

$$
t_{a} / t_{b}=\left(E_{b} / E_{a}\right)^{1 / \alpha}
$$

The mass of the panel is :

$$
\begin{aligned}
& m_{b}=\rho_{b} \cdot A \cdot t_{b} \\
& m_{a}=\rho_{a} \cdot A \cdot t_{a}
\end{aligned}
$$

where :

$\begin{array}{ll}\text { A } & \text { area of the panel } \\ \rho_{b} & \text { base material density }\end{array}$

$\rho_{a} \quad$ alternative material density 
The percentage of mass reduction is (per) :

$$
\begin{aligned}
(\text { per }) & =\left(m_{b}-m_{a}\right) / m_{b}=\left(\rho_{b} \cdot A \cdot t_{b}-\rho_{a} \cdot A \cdot t_{a}\right) / \rho_{b} \cdot A \cdot t_{b} \\
& =1-\left(\rho_{a} / \rho_{b}\right)\left(E_{b} / E_{a}\right)^{1 / a}
\end{aligned}
$$

With steel as the base material of $1 \mathrm{~mm}$ thickness and $210 \mathrm{GPa}$ stiffness and for different alternative materials, the properties of which are listed in Table 3., the thickness and percentage of weight reduction are obtained and listed in Table 4. The results show that boron / epoxy gives the least thickness and the highest percentage of weight reduction. This is due to the high value of transverse stiffness ( $214 \mathrm{GPa}$ ).

\section{REPLACING CONVENTIONAL INTEGRAL STRUCTURE MATERIAL BY COMPOSITE MATERIAL :}

In this case, box beams integrated with the body, are used instead of the traditional solid beam frame. The deformation under $2 \mathrm{KN}$ side force (in the $\mathrm{X}$ direction) on a $50 \times 50 \mathrm{~mm}$ box beam section is studied using finite element analysis for different materials with properties listed in Table 5. The results are shown in Fig.(12-15) and summarized in Fig. 16. The lowest deformation is associated with steel (Highest stiffness) followed by boron / aluminum. The mass per unit length of different beam materials is given in Fig. 17. The lowest value is associated with kevlar / epoxy (lowest density) followed by boron / aluminum. Thus boron / aluminum is considered as a good alternative material for steel box beams.

\section{CONCLUSIONS :}

- Modeling and analysis have been performed to anticipate the dimensions, weight and percentage of weight reduction when replacing the conventional vehicle frame and body materials (steel) by composite materials.

- Finite element modeling was used to calculate stresses and displacements of some vehicle structural parts.

- Increasing the steel fiber volume fraction, the percentage of frame weight reduction decreases due to the high density of fiber material (steel) relative to the matrix material (aluminum).

- Increasing the carbon fiber volume fraction, the percentage of frame weight reduction increases due to the low density of fiber material (carbon) relative to the matrix material (aluminum).

- The frame deformations under bending or torsion for both steel and carbon fiber composites with the same fiber volume fraction are nearly the same as the difference in stiffness between the two types of fibers is small.

- Due to the high yield strength of carbon fibers relative to the steel fibers, great reduction in cross section area, consequently weight of the carbon reinforced frame is possible. 
- The use of boron / epoxy in vehicle body panels gives the least thickness and the highest percentage of weight reduction.

- Boron / aluminum is a good alternative material for steel box beams used in integral vehicle structure.

\section{REFERENCES:}

[1] J.R.Dieffenbach, P.D.Palmer, and A.E.Masarin, Making the PNGV super car a reality with carbon fiber: pragmatic goal or pipe dream? J.SAE, v: $5, p$ : 4822-4835, 1996

[2] T.C.Moore, and A.B.Lovins, Vehicle Design Strategies to Meet and Exceed PNGV Goals, J.SAE, v: 5, p: 5331-5347, 1995.

[3] T.R.Banga, and N.Singh, Automobile Engineering, Khanna Publisher, Delhi, p: 1-10,1997.

[4] J.Y.Wong, Theory of Ground Vehicles, John Wiley \& Sons, 1978.

[5] J.Fairbrother, Teng., L.M.ibe, M.ibcam, Fundamentals of Vehicle Body Work, Hutchinson, London, 1986.

[6] F.P.Beer, E.Russell, Mechanics of Materials, McGraw-Hill, 1981.

[7] C.T.Herakovitch, Mechanics of Fibrous Composites, John Wiley \& Sons, 1997.

[8] K.G.Budinski, Materials properties and selection, p 139, John Wiley \& Sons, 1996.

[9] B.M. Rabeeh, M.M. Moussa, A. El-Soaly and H.M. Eitaher, Modeling Analysis and Mechanical Behavior of Different Metal Matrix Composite Structures, Proc. Of the $9^{\text {th }}$ Int. Conf. Of Applied Mechanics and Mechanical Engineering (AMME), Cairo, May 16-18, 2000, pp. 637-655.

[10] D.C. Chang, K.M. Wu, and J.R. Vell. The Regionai Stiffness Requirement of Body Panels for Material Substitution Design, J. S. A. E., v. 5, pp. 4429$4451,1985$.

\section{APPENDIX A : MATHEMATICAL MODEL OF FRAME LOADING}

Defining the Loads:

The main loads acting on the frame are the bending moment, and the torsion moment. The loads acting on the truck are shown in Fig. A1. Using the notations:

W Weight of the vehicle.

$W_{f} \quad$ Reaction on the front axle.

$W_{r} \quad$ Reaction on the rear axle.

$\mathrm{R}_{\mathrm{a}} \quad$ Aerodynamic resistance,

$R_{\mathrm{rf}} \quad$ Rolling resistance acting on the front axle.

$R_{\text {II }} \quad$ Rolling resistance acting on the rear axle.

$\mathrm{Ff}_{\mathrm{fl}} \quad$ Tractive effort acting on the front axle.

$\mathrm{F}_{\mathrm{r}} \quad$ Tractive effort acting on the rear axle.

h C.G height.

$h_{a} \quad$ height of aerodynamic resistance

L Wheel base. 


$\begin{array}{ll}\text { If } & \text { Front axle distance from the C.G. } \\ \text { I }_{\mathrm{s}} & \text { Rear axle distance from the C.G. } \\ \mathrm{a} & \text { truck acceleration } \\ \mathrm{g} & \text { gravity acceleration } \\ \mathrm{C}_{\mathrm{g}} & \text { truck center of gravity }\end{array}$

The equation of motion of a truck moving on a horizontal straight road :

$$
\frac{W \cdot a}{g}=F_{f}+F_{r}-R_{a}-R_{r f}-R_{r r}
$$

Since:

$$
\begin{aligned}
& F_{f}+F_{r}-\left(R_{a}+R_{r f}+R_{r r}+\frac{W \cdot a}{g}\right)=0 \\
& F=R_{a}+R+\frac{W \cdot a}{g}
\end{aligned}
$$

where:

$\mathrm{F} \quad$ The total tractive effort.

$\mathrm{R} \quad$ The total rolling resistance.

Taking the summation of moments will give :

$$
\begin{aligned}
& W_{1}=\frac{W \cdot l_{r} \cos (\theta)-R_{a} \cdot h_{a}-h \cdot W \cdot a / g \pm W \cdot h \sin (\theta)}{L} \\
& W_{r}=\frac{W \cdot l_{f} \cos (\theta)+R_{a} \cdot h_{a}+h \cdot W \cdot a / g \pm W \cdot h \sin (\theta)}{L}
\end{aligned}
$$

where: $\theta$ is the angle of slope in case of a truck climbing a slope.

For small angles we can take $\cos \theta=1, h_{a}=h, \sin \theta=0$.

$$
\begin{aligned}
& W_{f}=\frac{W \cdot l_{r}}{L}-\frac{h}{L}\left(R_{a}+W \cdot a / g\right) \\
& W_{r}=\frac{W \cdot l_{f}}{L}+\frac{h}{L}\left(R_{o}+W \cdot a / g\right)
\end{aligned}
$$

Then:

$$
\begin{aligned}
& W_{f}=\frac{W I_{r}}{L}-\frac{h}{L}(F-R) \\
& W_{r}=\frac{W \cdot l}{L}+\frac{h}{L}(F-R)
\end{aligned}
$$


For a rear wheel drive truck :

$$
F_{\max }=\frac{\mu \cdot W\left(l_{f}-f \cdot h\right) / L}{1-\frac{\mu \cdot h}{L}}
$$

For a front wheel drive truck:

$$
F_{\text {max }}=\frac{\mu \cdot W\left(l_{r}+f \cdot h\right) / L}{1+\frac{\mu \cdot h}{L}}
$$

For all wheel drive vehicle:

$$
F_{\text {mix }}=\mu \cdot W
$$

where:

$F_{\max } \quad$ Max tractive force

m Coefficient of adhesion between the tyres and the ground.

$f \quad$ Coefficient of friction between the tyres and the ground.

$$
R_{a}=\frac{\rho}{2} \cdot C_{D} \cdot A_{f} \cdot v^{2}
$$

where:

$\begin{array}{ll}\rho & \text { Air density. } \\ C_{D} & \text { Coefficient of drag of the truck } \\ A_{f} & \text { truck frontal area. } \\ V & \text { velocity of air relative to the truck }\end{array}$

v velocity of air relative to the truck.

From the previous analysis, the loads acting on a bearing system can be determined. For a slowly moving truck, the loads acting on the bearing system are the sum of the loads on the truck standing on a horizontal flat road and the additional loads which appear when one of the wheels rises on encountering a road irregularity. The main bending moment on the frame is calculated from the reactions acting on the truck in Eqs. (A8), (A9).

The bending moment is given by:

$$
M_{b}=W_{f} l_{f}=W_{r} l_{r}
$$

and the pitching moment $M_{p}$ is calculated as follows :

$$
M_{p}=0.5 \rho \cdot C_{M} \cdot A_{f} \cdot L \cdot V^{2}
$$

where

$\mathrm{C}_{\mathrm{M}} \quad$ pitching moment coefficient

L frame length

When one of the wheels is raised by a road irregularity relative to the other wheels, then an additional load will act on this wheel. In this case, a torsional 
moment as shown in Fig. A2 will be imposed on the load acting on the wheels of the vehicle standing on a horizontal and flat road, relative to the longitudinal axis. The maximum value of the moment acting on the wheels will be:

$$
T=0.5 B . H
$$

where:

$\mathrm{H} \quad$ The load on the less loaded axle.

B The wheel track of the corresponding axle.

Table 1 Truck technical data.

\begin{tabular}{|c|c|}
\hline Load on front axle (kN) & 53.655 \\
\hline Load on rear axle (kN) & 65.905 \\
\hline Total weight (kN) & 119.56 \\
\hline Max laden weight (kN) & 44.1 \\
\hline Front axle displacement from C.G.(m) & 1.66 \\
\hline C.G. height (m) & 1.675 \\
\hline
\end{tabular}

Table 2 Properties of matrix and fiber materials:

\begin{tabular}{|c|c|c|c|}
\hline Material & $\begin{array}{c}\text { Density } \\
\left(\mathrm{kg} \mathrm{/m} \mathrm{m}^{3}\right)\end{array}$ & $\begin{array}{c}\text { Tensile modulus } \\
(\mathrm{GPa})\end{array}$ & $\begin{array}{c}\text { Tensile strength } \\
(\mathrm{MPa})\end{array}$ \\
\hline Aluminum & 2710 & 70 & 310 \\
\hline $\begin{array}{c}\text { SAE 4340 } \\
\text { steel }\end{array}$ & 7830 & 200 & 1034 \\
\hline $\begin{array}{c}\text { Carbon fibers } \\
\text { AS-4 } \\
\text { (Hercules) }\end{array}$ & 1800 & 228 & 4000 \\
\hline
\end{tabular}

Table 3 Different materials properties.

\begin{tabular}{|c|c|c|}
\hline Material & $\begin{array}{c}\text { Density } \\
\left(\mathrm{kg} / \mathrm{m}^{3}\right)\end{array}$ & $\begin{array}{c}\text { Transverse modulus } \\
(\mathrm{GPa})\end{array}$ \\
\hline Boron/Epoxy & 2040 & 214 \\
\hline S-glass/Epoxy & 1800 & 44.1 \\
\hline E-glass/Epoxy & 2200 & 31.02 \\
\hline E-glass/Polyester & 1900 & 31 \\
\hline Carbon Fiber(60\%)/Epoxy & 1590 & 54.9 \\
\hline Titanium & 4430 & 110 \\
\hline
\end{tabular}


Table 4 Alternative materials thicknesses and their percentage of mass reduction.

\begin{tabular}{|c|c|c|}
\hline Material & $\begin{array}{c}\mathrm{t}_{\mathrm{n}} \\
(\mathrm{mm})\end{array}$ & $\begin{array}{c}\text { Percentage of weight reduction } \\
(\%)\end{array}$ \\
\hline Boron/Epoxy & 0.72708 & 746454 \\
\hline S-glass/Epoxy & 1.500548 & 53.82928 \\
\hline E-glass/Epoxy & 1.763357 & 33.68572 \\
\hline E-glass/Polyester & 1.763879 & 42.71163 \\
\hline Carbon Fiber(60\%)/Epoxy & 1.357096 & 63.11482 \\
\hline Titanium & 0.986645 & 25.28483 \\
\hline
\end{tabular}

Table 5 Different materials properties.

\begin{tabular}{|c|c|c|c|c|}
\hline Material & Aluminum & Steel & Kevlar / Epoxy & Boron/ Al \\
\hline Density $(\mathrm{kg} / \mathrm{m} 3)$ & 2870 & 7830 & 1380 & 2650 \\
\hline Axial modulus $(\mathrm{GPa})$ & 70 & 200 & 76.8 & 227 \\
\hline Transverse modulus $(\mathrm{GPa})$ & 70 & 200 & 55 & 139 \\
\hline Poisson's ratio $v_{12}$ & .33 & .32 & .34 & .34 \\
\hline Poisson's ratio $v_{23}$ & .33 & .32 & .37 & .36 \\
\hline Shear modulus $\mathrm{G}_{12}(\mathrm{GPa})$ & 52.2 & 147 & 2.07 & 57.6 \\
\hline Shear modulus $\mathrm{G}_{23}(\mathrm{GPa})$ & 52.2 & 147 & 1.4 & 49.1 \\
\hline
\end{tabular}

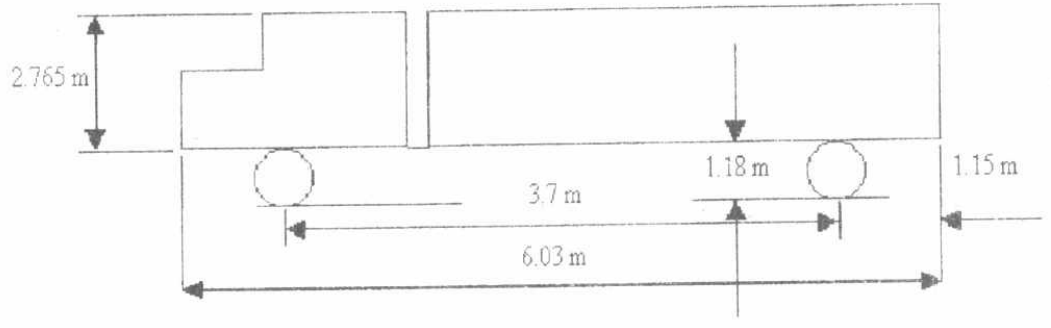

Fig. 1 Side view of the truck

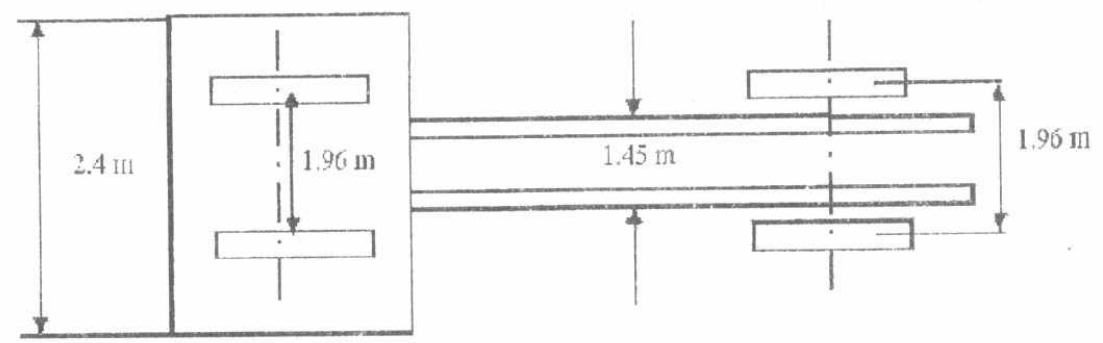

Fig. 2 Top view of the truck. 


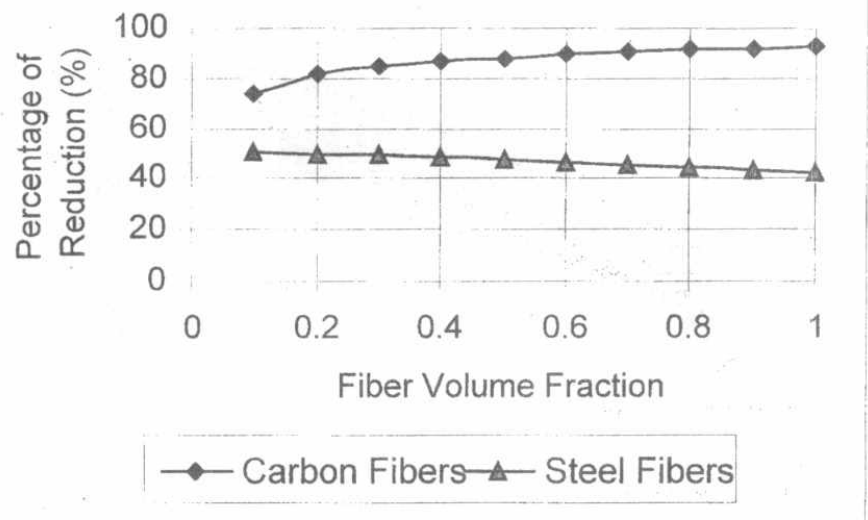

Fig. 3 Comparison between percentage of weight reduction for carbon, and steel fibers with fiber volume fraction.

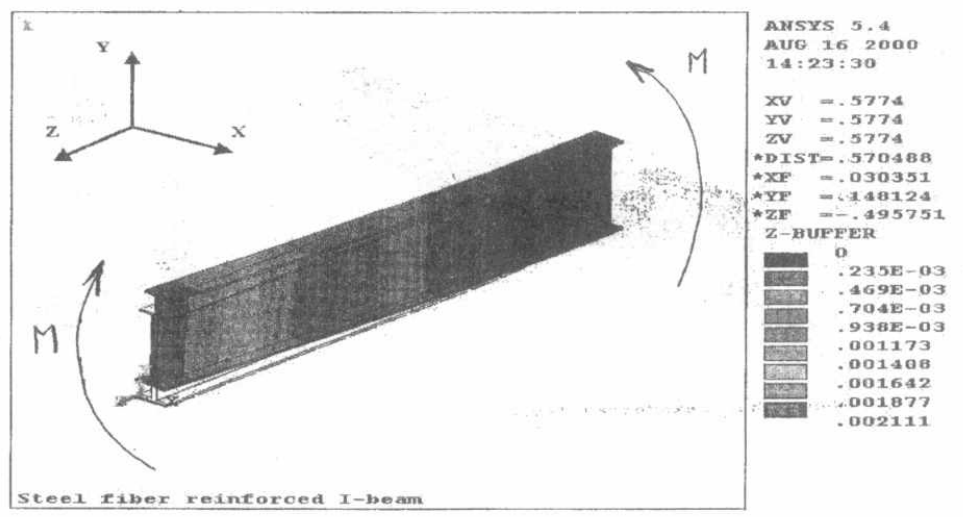

Fig. 4 Deformation [m] of steel fiber reinforced I-beam (vehicle frame) under bending 


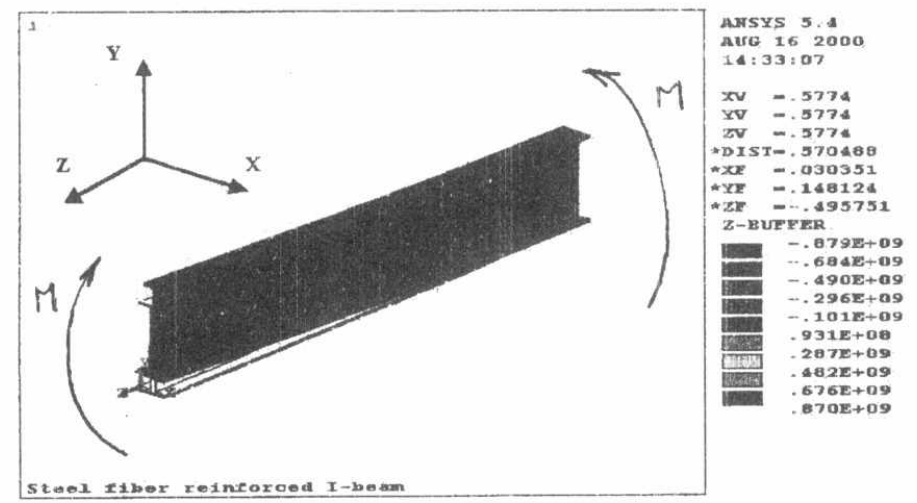

Fig. 5 Stress $[\mathrm{Pa}]$ in Z-direction of steel fiber reinforced I-beam (vehicle frame) under bending

thet

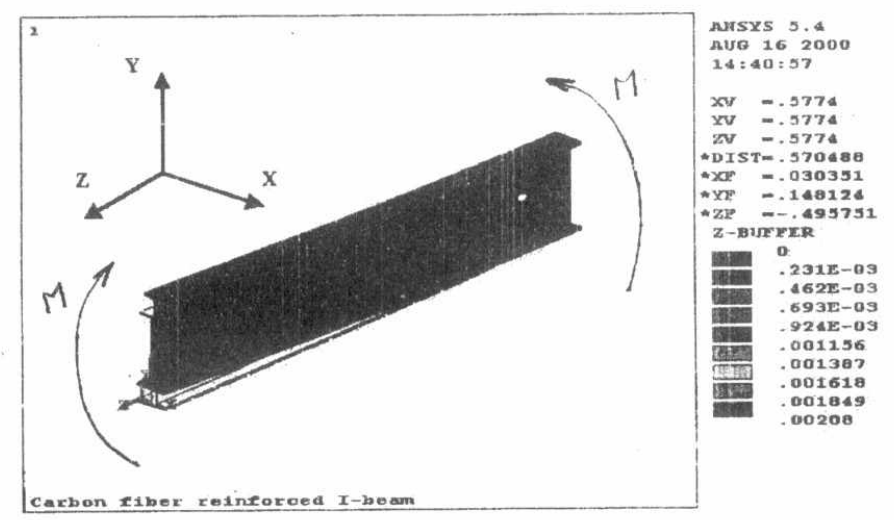

Fig. 6 Deformation $[\mathrm{m}]$ of carbon fiber reinforced I-beam (vehicle frame) under bending 


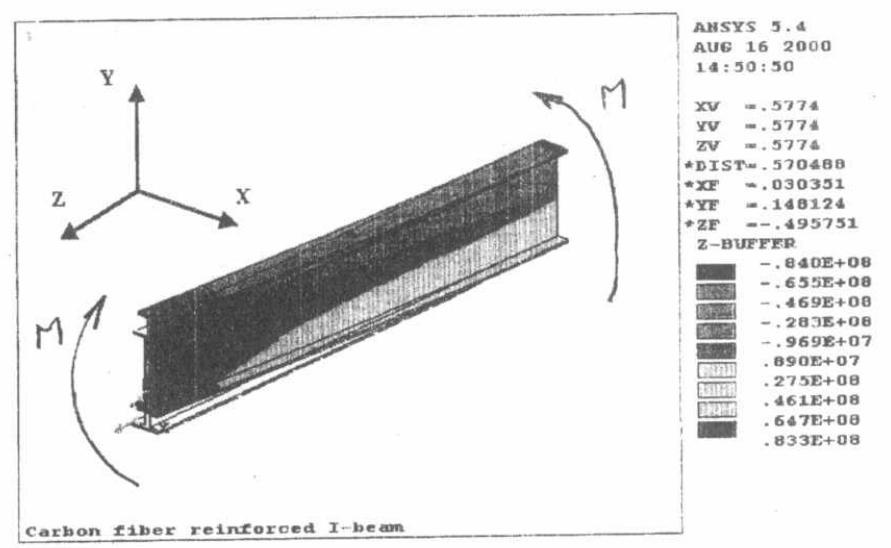

Fig. 7 Stress $[\mathrm{Pa}]$ in Z-direction of carbon fiber reinforced I-beam (vehicle frame) under bending

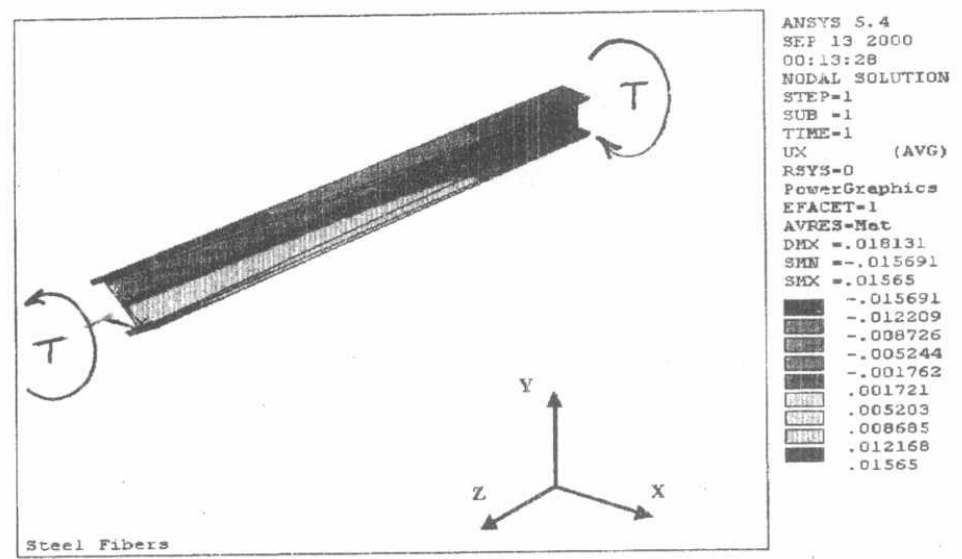

Fig. 8 Frame displacement $[\mathrm{m}]$ in the $X$ - direction for steel reinforced composite under torsion. 


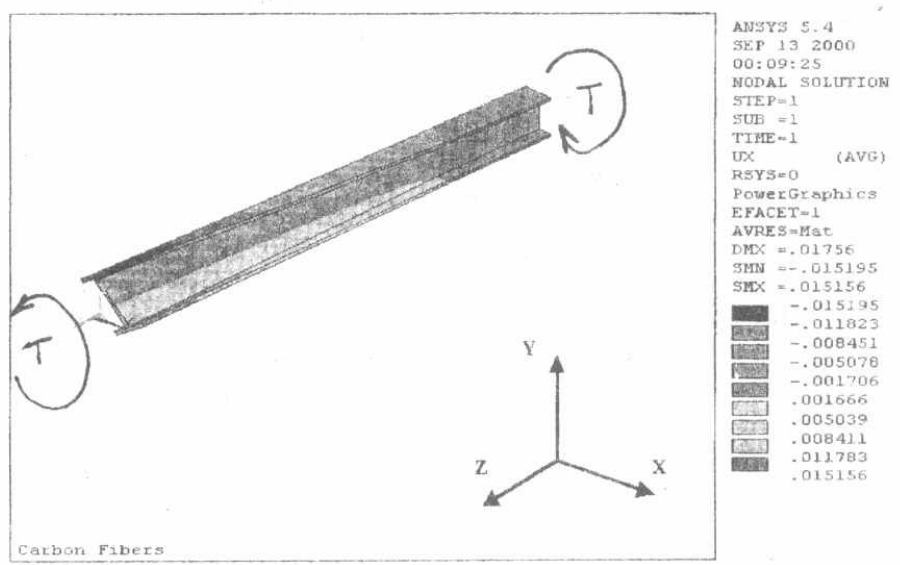

Fig. 9 Frame displacement $[\mathrm{m}]$ in the $\mathrm{X}$ - direction for carbon reinforced composite under torsion.

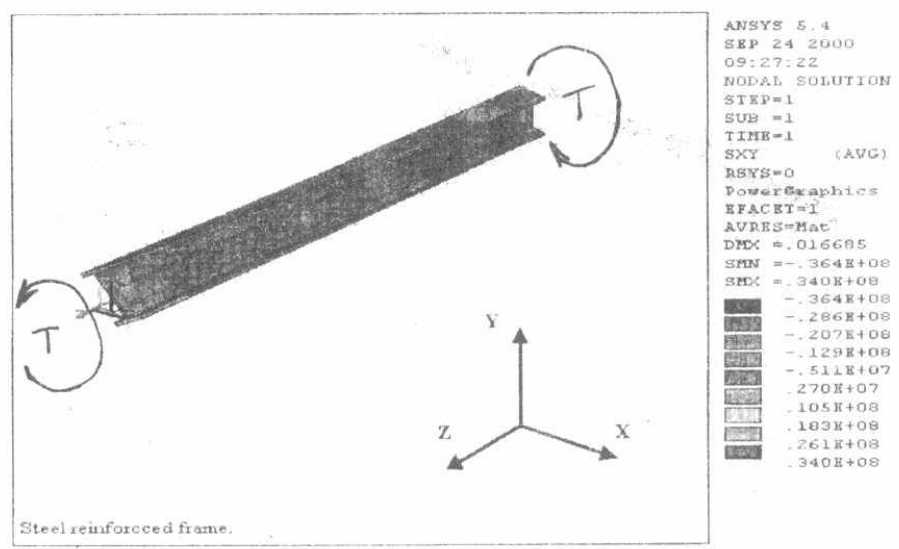

Fig. 10 Frame shear stress $[\mathrm{Pa}]$ in the $\mathrm{XY}$ - direction for steel reinforced composite under torsion. 


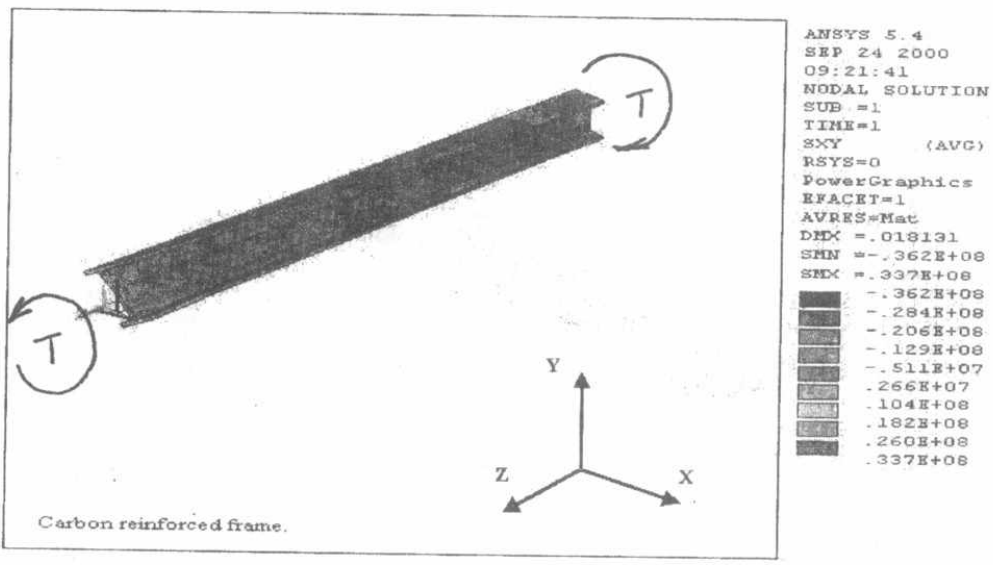

Fig. 11 Frame shear stress $[\mathrm{Pa}]$ in the $\mathrm{XY}$ - direction for carbon reinforced composite under torsion.

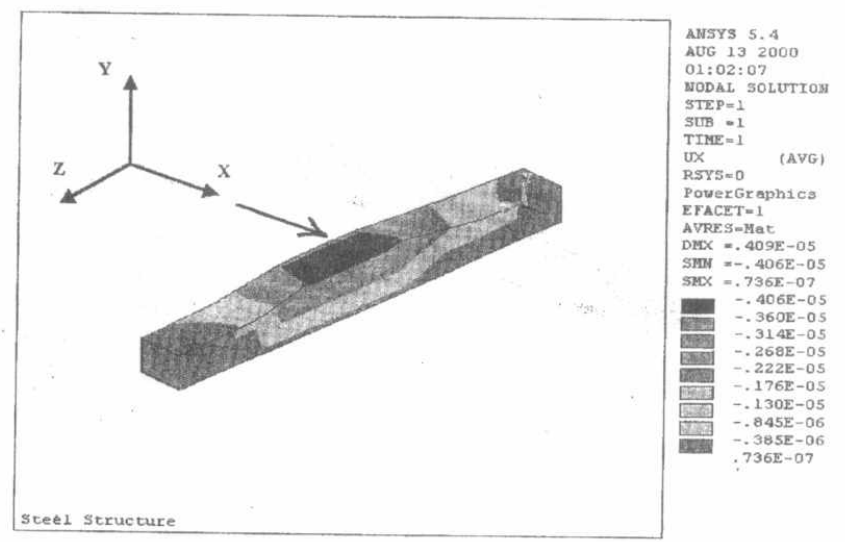

Fig. 12 Displacement $[\mathrm{m}]$ in the $\mathrm{X}$ - direction for steel box beam section. 


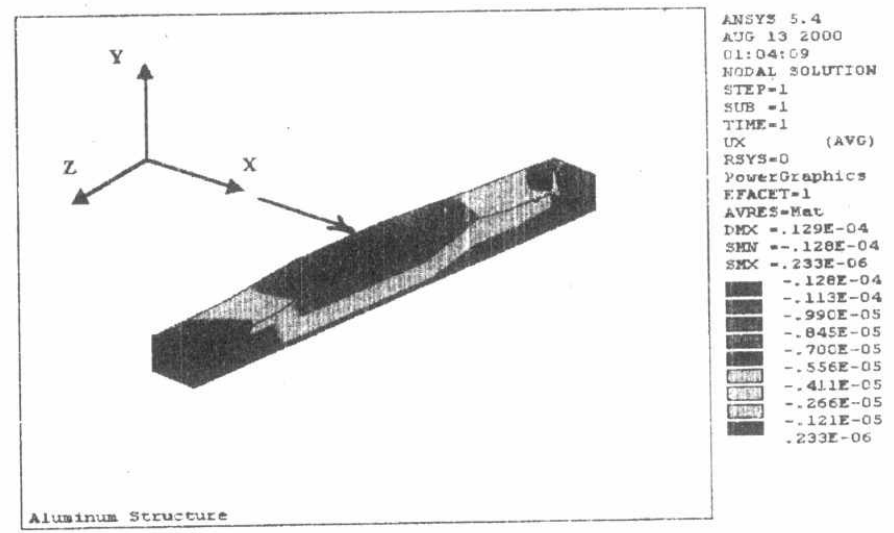

Fig. 13 Displacement [m] in the X-direction for aluminum box beam section.

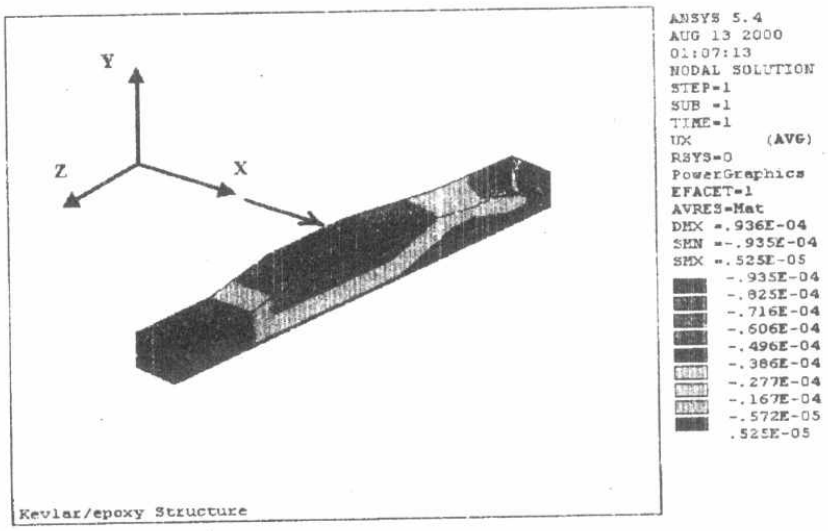

Fig. 14 Displacement $[\mathrm{m}]$ in the $\mathrm{X}$-direction for kevlar / epoxy box beam section. 


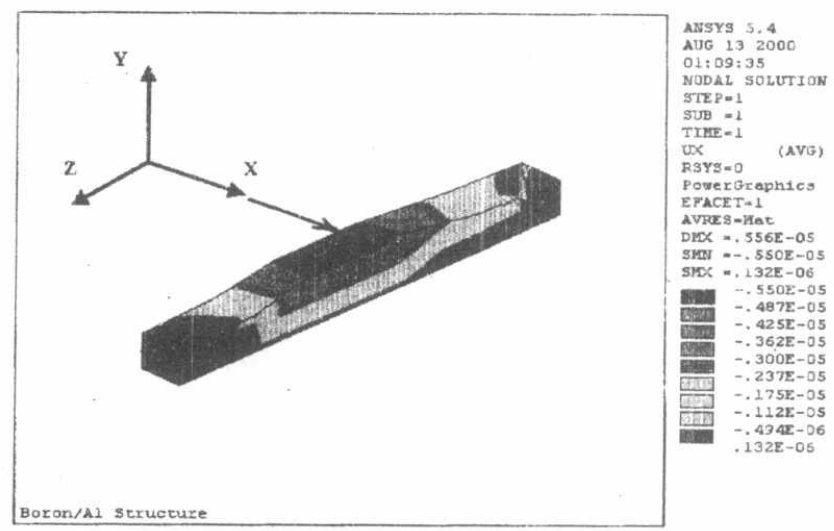

Fig. 15 Displacement in the X-direction for boron / aluminum box beam section $[\mathrm{m}]$

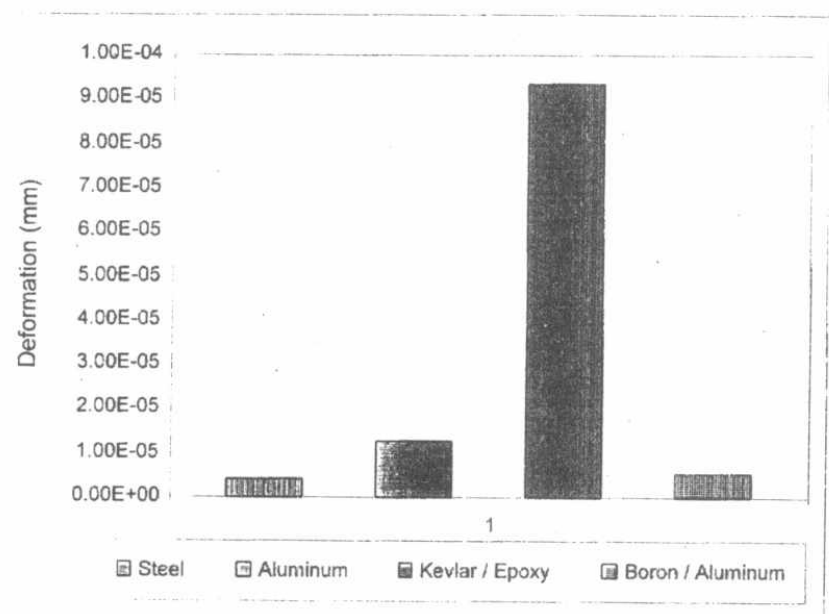

Fig. 16 Deformation in the transverse direction of different materials. 


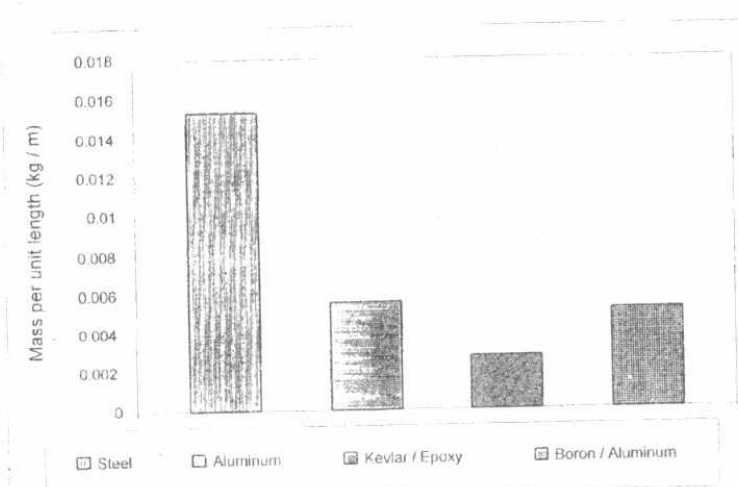

Fig. 17 Mass per unit length for different materials.

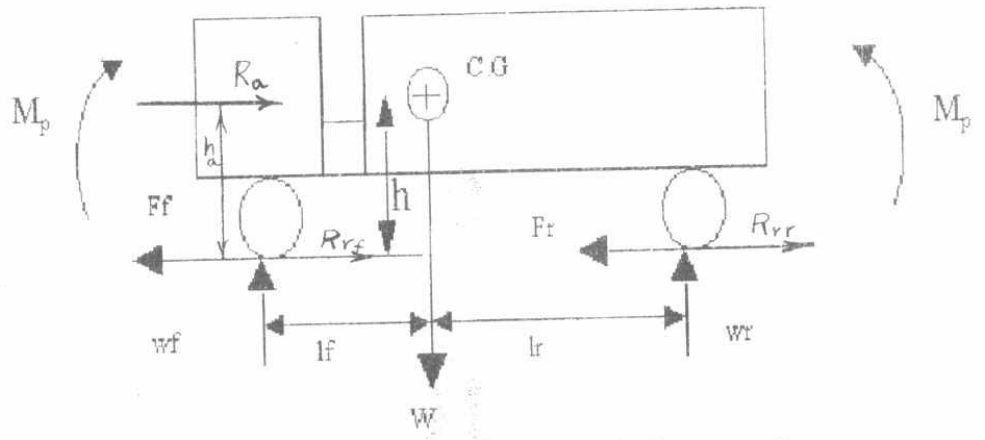

Fig. A1 Loads acting on the truck during operation.

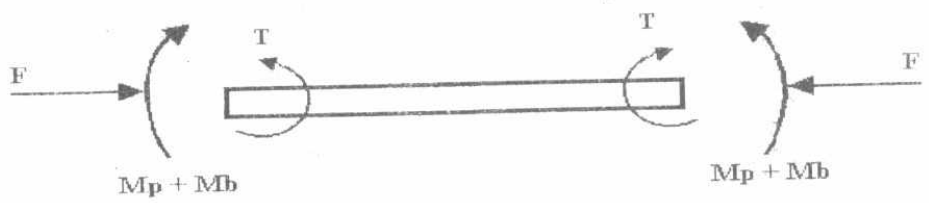

Fig. A2 Loads acting on the frame during operation. 